\title{
A Critical Discourse Analysis of Biden's Victory Speech from the Perspective of Systemic Functional Grammar
}

\author{
Chenchen Pu \\ School of Foreign Languages, Southwest Petroleum University, Chengdu, Sichuan, China
}

\begin{abstract}
In political discourse, the speeches of the president of the United States have always been the focus of linguistic scholars. This paper by using Halliday's systemic functional Grammar, analyzes the text of President Biden's speech from ideational, interpersonal and textural metafunctions and tries to figure out how he convinced and inspired American and reveal the power relations behind the text.
\end{abstract}

Keywords: Systemic Functional Grammar; Critical discourse analysis; Biden's Victory Speech

\section{Introduction}

In 2020, the novel coronavirus epidemic swept the world, the global economy started to reverse, and the international political situation was turbulent. There is no doubt that coronavirus epidemic has become the biggest "black swan event" of these years. The United States is the strongest country in the world, but it is also one of the worst countries to deal with COVID-19. This reflected that the Trump administration lacked of governance capacity facing with unexpected incident of public health, thus which led to disappointment of the American people to the Republican Party. In this context, the United States conducted the 2020 presidential election, and the Democratic candidate Joseph Biden declared victory. The information behind Biden's victory speech will largely affect the U.S. national policy, governance philosophies and changes of the international situation.

Critical discourse analysis (CDA) is a discourse analysis method developed by Western linguists represented by Flower in the 1970s and 1980s. It not only pays attention to what language is, but also studies why language is so. Therefore, we can get more knowledge about Biden's administration by analyzing Biden's victory speech.

\section{Literature Review}

\subsection{Development of Critical Discourse Analysis Theory}

Norman Fairclough (1988) pointed out that critical discourse analysis believes that discourse is the language of social activities, while Fowler (1979) believes that discourse is a part of social organization and social process. Discourse is a systematic way of organizing the meaning and value given by social system. A discourse is to define what is possible or impossible to say or make about the relevant system Description and definition. In order to more accurately understand how language constructs and spread knowledge, critical discourse analysis needs to integrate and absorb the core ideas of different disciplines such as philosophy, linguistics, sociology and literary criticism on the premise of certain basic principles. Norman Fairclough and Ruth Wodak pointed out, generally speaking, critical discourse analysis can be summarized into eight principles: (1) Social problems are the core of critical discourse analysis; (2) Discourse can reflect power relations; (3) Society and culture can be constructed through discourse; (4) Discourse is the carrier of some ideology; (5) Discourse is inseparable from history, and it can not exist independently of history; (6) There is no direct relationship between discourse and society, and there exists a certain medium between them; (7) Discourse analysis is interpretative, and different discourse receivers may have different interpretations to the same materials; (8) Discourse is a kind of social behavior. All the eight principles mentioned above have gradually developed into the basic concepts of critical discourse analysis.

Many Chinese scholars also summarize and compare critical discourse analysis from different angles. Xin Bin (1996) first introduced the western critical discourse analysis theory in his published paper, and based on this theory, he carried out critical discourse analysis of Chinese and English news discourse, especially the intertextuality, dialogism and reporting speech of news discourse. Ji Yuhua (2009) evaluated and classified the multi perspective researches on "Discourse" in different academic fields, focusing on the definition of "Discourse" by the critical discourse school from the perspective of social politics. Li Juyuan (2014) redefined the core concept of critical discourse analysis. They believe that ideology and power relations run through all the processes of language use. Critical discourse analysis should focus not only on some discourse research, but on all discourse research. Wu Jianguo (2015) pointed out that critical discourse analysis also should absorb more ideas of sociological and philosophical theories, though it is based on linguistic theory.

\subsection{Approaches of Critical Discourse Analysis}

There are two main models of critical discourse analysis: Fairclough's critical discourse analysis model and James Paul Gee's critical discourse analysis model. Fairclough constructed a three-dimensional framework to discuss the dialectical relationship between discourse and social structure from the perspectives of discourse analysis, discourse practice and social practice. Gee uses four analytical tools and six constructions as theoretical research tools to construct a unique critical discourse analysis model. Halliday's three metafunctions of language are the theoretical basis of 
discourse analysis. Fairclough and Gee both used Halliday's systemic functional linguistics theory for reference in discourse analysis to discuss the function and significance of discourse at the discourse level from the aspects of vocabulary and grammatical structure.

\subsection{Critical Discourse Analysis Based on Corpus}

Baker and Mc Enery (2005) pointed out that corpus can provide researchers with a variety of naturally occurring language forms, so that researchers can have an objective and systematic understanding of the language in use. At the same time, corpus can make researchers know the most widely used or little-known language use examples. Hunston (2002) reckoned that corpus can also help people identify the implied meaning behind repeated language, and those vague language phenomena gradually can be clarified in this process, which sometimes brought unexpected discoveries to researchers. Hardt Mautner, who is the first scholar advocating the corpus technology for critical discourse analysis, thought that the corpus provided us with a strong basis for quantitative analysis, and the corpus index function effectively broke the boundary between quantitative and qualitative research. Based on these, more and more scholars begin to study it from the perspective of corpus technology and critical discourse analysis. These studies mainly identify the internal meaning of discourse through the observation of word frequency, subject word index, collocation, grammatical structure and form. Based on Biden's victory speech, this paper mainly uses the method of systemic functional grammar to make a critical discourse analysis of the American presidential victory speech from the three metafunctions of language.

\section{Analysis of Biden's Victory Speech}

Based on Halliday's theory of the three metafunctions of language, this paper analyzes Biden's victory speech in order to reveal Biden's language characteristics and the connotation behind his discourse.

\subsection{Ideational Metafunction Analysis}

Ideational function refers to convey new information, to communicate a content, which is unknown to hearer. It mainly consists of includes "transitivity" and "voice". The transitive system includes six processes: material process, mental process, relationship process, behavior process, speech process and existential process. This paper focuses on the first three processes.

\subsubsection{Material Process}

Material process is used to show the process of doing something, involving process, actor and goal. And the process is generally expressed by action verb.

(1) I pledge to be a president who seeks not to divide but unify.

(2) I sought this office to restore the soul of America, to rebuild the backbone of this nation, the middle class, and to make America respected around the world again.

(3) And she has dedicated her life to education, but teaching isn't just what she does.

(4) Folks, our work begins with getting COVID under control.

As we can see from the above sentences indicating the material process, the verb of "pledge" in the first sentence shows Biden's determination and commitment to keep all ethnics harmonious and the United States united, and at the same time, he cleared his political viewpoint. In the second sentence, the word "restore" expresses Biden's desire to help the United States regain the American spirit, and "rebuild" shows that his political goal is to serve the middle class in the U.S., which not only inspires Americans, but also well expresses his long-cherished political wish in the next four years. In the third sentence, Biden used his wife's identity of teacher to show his wife's lifelong dedication to education, and thus narrows the relationship between him and educators, and also shows that he will provide more support for education field. In the fourth sentence, the goal in the material process is controlling COVID-19, which is the beginning of the government work. It not only expresses the aspirations of Americans who are seriously affected by the epidemic, but also shows that Biden's administration values the work of controlling coronavirus and their confidence in defeating coronavirus. On the one hand, these sentences show the real current situation of the United States, on the other hand, they also express the presidential candidate's general arrangement and planning for the future administration work, in order to regain the people's trust in their country and try to change the current situation.

\subsubsection{Mental Process}

Mental process refers to the process of psychological activities such as perception, reaction and cognition. This process includes sensor and phenomenon. Generally, speaker use these words - see, like, think and so on to present this process. In Biden's speech, there are many verbs expressing cognition, especially the word "believe".

(5) I believe it's this: Americans have called upon us to marshal the forces of decency, the forces of fairness, to marshal the forces of science and the forces of hope in the great battles of our time.

(6) And I believe at our best, America is a beacon for the globe.

(7) Let us be the nation that we know we can be.

Biden conveys his confidence in the United States through verbs such as believe and know. "Believe" presents firm confidence of Biden to that American people can make the United States greater again. In his speech, we can easily know that he wants to make the United States a beacon all over the world, make all American people feel the prosperity of the motherland, awaken the faith of all Americans, and indirectly express that every American should bear responsibilities and obligations in real life and strive to revive the American spirit.

\subsubsection{Relational Process}

Relational process is a process that reflects the relationship between things. It can be divided into attributive and 
identifying types. The former describes what attributes a certain object has or what type it belongs to. The latter expresses identical properties of two entities.

\section{(8) America is a beacon for the globe.}

(9) (Ahead to an America that never gives up, never gives in.) This is a great nation.

(10) (And to make progress, we have to stop treating our opponents as our enemies.) They are not our enemies. They are Americans. They are Americans.

The first and second sentences indicate that Biden thinks America is the best country in the whole world and all American should keep working hard to keep their honor. It is obvious that the intention of Biden is to cheer Americans up. The third sentence is aimed at the supporters who voted for Biden. Those American citizens who voted for Donald Trump are not their enemies, but Americans. He hopes that all the people can unit, and are not hostile to each other because of different politics. What's more, he spoke "They are Americans" twice, which expresses intensity and strong appeal.

\subsection{Interpersonal Metafunction Analysis}

In addition to expressing the activities of the external world and the inner mind, language can also show the speaker's identity, status, attitude, motivation and so on.

\subsubsection{Mood}

Mood provides us with the speech function and it emphasizes the role of speakers play. Mood consists of two elements: the subject and the finite. According to the statistics, in Biden's speech, there are only three imperative clauses and two interrogative clauses. The other sentences are all declarative clauses. That is to say, Biden mainly used declarative clauses to give information, including hopes, attitudes, promises to his audiences. That is because declarative clauses can make the speech more solemn and objective. For example, "We cannot repair the economy, restore our vitality or relish life's most precious moments, hugging our grandchildren, our children, our birthdays, weddings, graduations, all the moments that matter most to us until we get it under control." and "I will spare no effort, none, or any commitment to turn around this pandemic." imply that Biden puts controlling epidemic first.

In addition, the three imperative clauses are all beginning with "let", and they are picked out as following.

(11) Let this grim era of demonization in America begin to end here and now.

(12) Let us be the nation that we know we can be.

(13) $\cdots \cdot \cdot$ but now let's give each other a chance.

As is common, the imperative structure can resonate with audience, because they can find the same background and the common interests. So Biden chose imperative clauses can narrow the distance between them and the American audience when making speech, so as to make it easier for them to break through the psychological defense line of the audience, enhance their sense of identity and belonging, transmit ideas, and obtain support from American people.

As for interrogative clauses, there are only two. Biden used them to trigger people to consider what they will do in the next four years, and then he can easily state his own work goals. The interrogative clauses are as following.

(14) Now this campaign is over, what is the will of the people?

(15) What is our mandate?

\subsubsection{Modality}

Modality is a very important part of interpersonal metafunction, which means that the speaker makes a judgment on the effectiveness of his proposition, or requires the other people to undertake obligations in the order, or expresses his personal will in the proposal. It shows the speaker's cognitive, emotional and willing attitude. It is a complex functional field, which is mainly reflected in the use of modal verbs. The speaker's attitude and view are often contained in modal verbs, and different modal verbs have different modal meaning values. Modal verbs have three modal values: high, medium and low. Modal verbs of high value include must, have to, be to, ought to and need, of medium value include will, would, shall and should, while of low - can, could, may and might. Political discourse is often persuasive and inspiring. The use of modal verbs can characterize the discourse characteristics of this discourse. By studying the modal system of the discourse, we can understand how much responsibility the speaker has taken for the language he speaks, how likely it is to realize his commitments, and whether his obligations are clear. In addition, we can also understand the speaker's attitude towards the listener, as well as the social distance and power relationship between them. There are 19 modal verbs in the text of Biden's victory, and the relevant distribution is as follows:

Table 1: The frequency of modal verbs

\begin{tabular}{|c|c|c|c|c|c|}
\hline Modal verbs & can (cannot) & will & have to & would & must \\
\hline Frequency & 6 & 8 & 1 & 1 & 3 \\
\hline
\end{tabular}

It can be seen from the above table that Biden uses "will" frequently in his speech to indicate his prediction and expectations for his future work. And then, the second most frequent modal verb is "can", that is to say, the speaker's attitude is generally euphemistic and peaceful. Unlike the high-value word "must" which gives people a strong feeling, Biden's expression leaves more acceptance space for the listener. There are some exemplified sentences.

(16) On Monday I will name a group of leading scientists and experts as transition advisors to help take the Biden-Harris COVID plan and convert it into an action blueprint that will start on January the 20, 2021.

(17) We can do it.

Pronouns are also the very essential in modality, which can convey a variety of interpersonal meanings. Many speakers prefer to use personal pronouns to convey "subtle 
interpersonal meaning". In the speech of Biden, the most frequent pronouns is first person. This is because Biden wanted to show he and Americans were on the same front.

\subsection{Textural Metafunction Analysis}

Discourse is the production of social practice. We can analyze the potential connotation of the speaker's speech content through discourse. Xin Bin proposed that nominalization and passivization hide the information of ideology. Let's take this sentence as an example - "Let this grid era of demonstration in America begin to end here and now." "Demonization" is the noun form of "demonize", which showed the panic situation surrounded by epidemic in the United States, and highlighted the dark politics and serious epidemic that the people were suffering, and implied criticism of Trump's series of miscalculation. "I believe at our best, America is a beacon for the globe." Biden used the concept of "beacon" to metaphor that the United States is the light and direction pursued by the whole world. The United States is the pride of all American people. And people should believe that he can lead them to a better future. In this sentence, Biden clearly showed his political goals. "The Bible tells us, "to everything there is a season: a time to build, a time to reap, and a time to sow and a time to heal."' This sentence uses a pun. Biden cleverly quoted the old saying of the Bible to express that United States not only had come to an era of healing and needs to invest more medical resources to treat patients in the background of COVID-19, but also showed that the new administration would be the "doctor" who would restore the social order after the Trump administration.

\section{Conclusion}

Critical discourse analysis can make people analyze discourse more objectively and rationally, so as to explore the implied meaning of language and its relationship with power and society. Based on the data statistics of corpus, this paper combines quantitative analysis with qualitative analysis, and discusses the deep meaning hidden behind Biden's victory speech from the aspects of ideational, interpersonal, textural metafunctions. From Biden's speech, it can be seen that he used a variety of language strategies to show his political position of serving the middle class, express the political goal of reshaping the soul of the United States, call on all people to struggle for American future and unit all audience to work together for the United States. Biden successfully constructed the image of a new generation of American president who is modest and practical.

\section{References}

[1] Fairclough, Norman. Critical Discourse Analysis[M]. Longman, 2010.

[2] Terry. Methods of critical discourse analysis[M]. Peking University Press, 2014.

[3] Xin Bin. Critical Linguistics: Theory and Application[M]. Shanghai Foreign Language Education Press, 2002.

[4] Torfing, Jacob. New Theories of Discourse[M]. Blackwell Pub, 1999.
[5] Wodak, R., M. Meyer. Methods of critical discourse analysis[M]. Sage, 2001.

[6] Waugh, L. R., et al. Critical Discourse Analysis: Definition, Approaches, Relation to Pragmatics, Critique, and Trends[M]. Springer International Publishing, 2016.

[7] Fairclough, N.. Language and power[J]. Language in Social Life, 2001.

[8] Xin Bin. Critical Linguistics and the Critical Analysis of English News[J]. Foreign Language Education, 2000.

\section{Author Profile}

Chenchen Pu, postgraduate student of Southwest Petroleum University, major in Foreign Linguistics and Applied Linguistics. 